\title{
Whole-Exome Sequencing Identifies a Novel TRPM4 Mutation in a Chinese Family with Atrioventricular Block
}

\author{
Yi Dong, ${ }^{1,2}$ Ran Du, ${ }^{2}$ Liang-liang Fan $\mathbb{D}^{2},{ }^{2}$ Jie-yuan Jin $\mathbb{D}^{2},{ }^{2}$ Hao Huang, ${ }^{2}$ Ya-qin Chen, ${ }^{3}$ \\ Dan-dong Bi $\left(\mathbb{C}^{1}{ }^{1}\right.$ and Rong Xiang ${ }^{2}{ }^{2}$ \\ ${ }^{1}$ Department of Patient Service Center, Xiangya Hospital of Central South University, Changsha 410008, China \\ ${ }^{2}$ Department of Cell Biology, School of Life Sciences, Central South University, Changsha 410013, China \\ ${ }^{3}$ Department of Cardiology, The Second Xiangya Hospital of Central South University, Changsha 410078, China
}

Correspondence should be addressed to Dan-dong Bi; xy-bidandong@csu.edu.cn and Rong Xiang; shirlesmile@csu.edu.cn

Received 13 May 2020; Revised 24 September 2020; Accepted 2 February 2021; Published 19 April 2021

Academic Editor: Salvatore Gallone

Copyright ( 2021 Yi Dong et al. This is an open access article distributed under the Creative Commons Attribution License, which permits unrestricted use, distribution, and reproduction in any medium, provided the original work is properly cited.

\begin{abstract}
Atrioventricular block (AVB) is a leading cause of sudden cardiac death, and most of AVB cases are presented as autosomal dominant. The electrocardiogram of AVB patients presents an abnormal progressive cardiac conduction disorder between atria and ventricles. Transient receptor potential melastatin 4 (TRPM4) is a nonselective $\mathrm{Ca}^{2+}$-activated cation channel gene defined as a novel disease-causing gene of AVB. So far, 47 mutations of TRPM4 have been recorded in Human Gene Mutation Database. The aim of this study was to explore the relationship between TRPM4 mutation and pathogenesis of AVB. We investigated a Chinese family with AVB by whole-exome sequencing. An arrhythmia-related gene filtering strategy was used to analyze the disease-causing mutations. Three different bioinformatics programs were used to predict the effects of the mutation result. A novel mutation of TRPM4 was identified (c.2455C>T/p.R819C) and cosegregated in the affected family members. The three bioinformatics programs predicted that the novel mutation may lead to damage. Our study will contribute to expand the spectrum of TRPM4 mutations and supply accurate genetic testing information for further research and the clinical therapy of AVB.
\end{abstract}

\section{Introduction}

Inherited progressive cardiac conduction disease (PCCD) is defined as an abnormal progressive cardiac conduction disorder [1], in which atrioventricular block (AVB) is characteristic by the presence of heart conduction block between atria and ventricle on 12-lead electrocardiogram (ECG). This abnormality of cardiac conduction will elevate the risk of sudden cardiac death, which will become a heavy burden for both family and society [2-4]. AVB can be classified into three tiers according to the extension degree and ECG. Firstdegree AVB often shows a 0.2 -second delay of the PR interval in ECG [5]. Second-degree AVB remains poorly understood as it can present in all ages without obvious symptoms. Previous studies recorded complex, variable rhythm patterns like various atrioventricular conduction and changing atrial rhythms in second-degree AVB patients [6, 7]. Varying clin- ical figures like tiredness, chest pain, shortness of breath, or syncope are associated with third-degree AVB patients. Besides, third-degree AVB patients generally necessitate pacemakers for survival $[8,9]$.

The transient receptor potential melastatin 4 (TRPM4) encodes a nonselective $\mathrm{Ca}^{2+}$-activated cation channel which is highly expressed in Purkinje fibers and nodal tissue [10]. Activated TRPM4 channels act on membrane repolarization and impact $\mathrm{Ca}^{2+}$ driving force which are essential for regulating $\mathrm{Ca}^{2+}$ oscillation frequency in cardiomyocytes $[11,12]$. Mutations in TRPM4 were found to be associated with various inherited cardiac conduction disease such as progressive familial heart block type I (PFHB1), Brugada syndrome (BrS), right bundle branch block (RBBB), bradycardia, and AVB [13-15].

In this study, we investigated a typical phenotypic family with a history of syncope and sudden cardiac death. By applying whole-exome sequencing (WES) and arrhythmia-related 
gene filtering, we identified a novel heterozygous mutation (c.2455C>T/p.R819C) in TPRM4 (NM_001195227) that might be the nosogenesis in this AVB family.

\section{Materials and Methods}

2.1. Subjects. This study was approved by the review board of Xiangya Hospital of the Central South University. The proband and the relatives who participated in the study have been given informed consent letters. Blood was collected from the proband and related family members. The proband was examined by standard 12-lead ECGs.

2.2. Whole-Exome Sequencing. Genomic DNA was extracted with a DNeasy blood and tissue kit (Qiagen, Valencia, CA). Exome capture, high-throughput sequencing, and common filtering were delivered to the Novogene Bioinformatics Institute (Beijing, China). All the exomes were captured by means of Agilent SureSelect Human All Exon V6 kits and were sequenced by an Illumina HiSeq2000 platform. Filtering strategies were the same as our previous study [16, 17].

2.3. Mutation Analysis. PolyPhen-2, SIFT, and MutationTaster bioinformatics programs were used to predict the effects of the mutations detected by WES. The mutation which was most likely to lead to the disease was verified by Sanger sequencing. Segregation analysis was performed among all the family members. Primer pairs were designed by the PrimerQuest Tool (http://sg.idtdna.com/Primerquest/Home/Index), and the sequences of primers will be provided upon request.

\section{Results}

3.1. Clinical Subjects. We identified a Chinese family with AVB (Figure 1(a)). The proband (III-1) is a 10-year-old girl from Hunan province, which presented dizziness for 4 days. She was sent to Xiangya Hospital due to syncope. The 12-lead ECGs showed a high-grade atrioventricular conduction block (Figure 1(b)). She was diagnosed as third-degree AVB. Besides, other two family members (I-1 and II-2) also had a history of AVB. Moreover, her grandmother (I-1) died of sudden cardiac death (Table 1).

3.2. Genetic Analysis. To identify the potential gene mutation leading the AVB in this family, WES was applied. WES yielded $10.92 \mathrm{~Gb}$ data with $99.7 \%$ coverage of target region, and $98.7 \%$ of targets were covered over 10x. After alignment and single-nucleotide variant (SNV) calling, 54725 variants were found in this family. Data filtering excluded shared common variants from the 1000 Genomes Project, YH, dbSNP132, and ESP databases; 487 unique SNPs were identified. Arrhythmia-related genes were used to filter candidate mutations in which 10 mutations were identified (Table S1). All filtered variants were predicted by 3 different bioinformatics programs (Table 2). Based on the prediction results, among all of the 10 mutations, only TRPM4 (c.2455C>T/p.R819C) was regarded as the diseasecausing gene by all the bioinformatics programs. The value of MAF of the novel mutation (p.R819C) in the Asian population was zero. Therefore, we infer that the TRPM4 mutation is the pathogenic cause of the proband.

To further confirm the TRPM4 mutation is responsible for the AVB, Sanger sequencing was employed to examine the mutation segregated within this family. The result indicated that the novel missense mutation of TRPM4 is cosegregated with the affected AVB members in this family, but not with the normal members (Figure 1(c)). Alignment analysis of TRPM4 amino acid sequences from human, mouse, rat, etc., showed that the site was highly conserved (Figure 2(a)). It is a further indication that the TRPM4 (c.2455C>T/p.R819C) variant lead to AVB among this family.

\section{Discussion}

In this study, a proband with a high-grade atrioventricular conduction block and a history of syncope was explored by WES combined with arrhythmia-related gene filtering. A novel missense mutation TRPM4 (c.2455C>T/p.R819C) was identified, which is located in the exon 18. This missense mutation was further confirmed in other family members by Sanger sequencing, which was accounted for the cosegregation of the members with the disease phenotype.

TRPM4 plays a crucial role in the cardiac conduction system. Immunohistochemistry results show that TRPM4 is highly enriched in ventricular cardiomyocytes and is highest in Purkinje fibers [18]. In previous studies, Mathar et al. have provided that TRPM4 knock-out mice resulted in a shortened ventricular action potential and an increased $\beta$-adrenergic-dependent ventricular systole [19]. In 2015, Jacobs et al. revealed the silence of TRPM4 mice appeared severe cardiac muscle necrosis by obstructing the left anterior descending artery [20]. The current study further supported the idea of the role of TRPM4 in AVB. A developed ventricular fibrillation and idioventricular rhythm had been recorded in overexpression of TRPM4 [21]. Thus, our study regards TRPM4 mutation as the result of AVB among 10 identified mutations.

In 2009, Kruse et al. revealed the first TRPM4 mutation in progressive familial heart block type I patient. E7K, a gain of function variant, would cause an elevated TRPM4 channel density and affect the sensibility of Small Ubiquitin MOdifier conjugation (SUMOylation) [22]. Up till now, 47 mutations in TRPM4 have been recorded in the Human Gene Mutation Database (http://www.hgmd.cf.ac.uk/ac/index.php). Most of these mutations are located in the cytoplasmic N-terminus domain, which is important for $\mathrm{Ca}^{2+}$ sensitivity, desensitization, and voltage dependence of the TRPM4 channel (Figure 2(b)) [18]. According to previous studies, mutations (Y790R and G844D) mapped to the first intracellular loop showed a gain of function in TRPM4. Besides, cotransfection experiment of G844D with Ubc9 displayed an increased current density which will lead to abnormal SUMOylation and dysfunction of endocytosis [23, 24]. Our novel mutation (c.2455C>T/p.R819C) of TRPM4 is located in a highly conserved domain, which shares a common intracellular loop with G844D. Thus, we suppose that the alternation from alkaline amino acid (Arg) to polar but uncharged amino acid (Cys) may also affect the channel density at cell surface like 


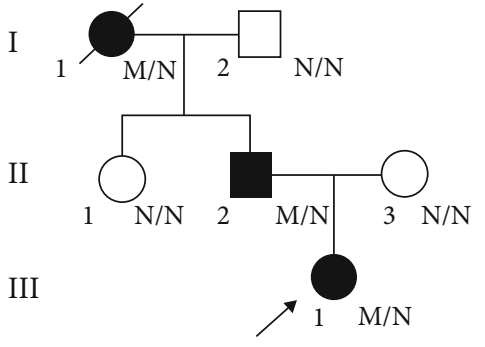

(a)

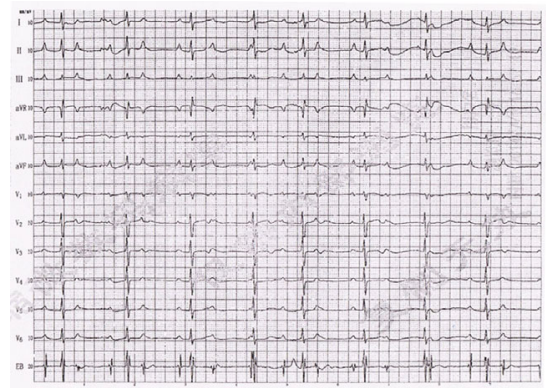

(b)

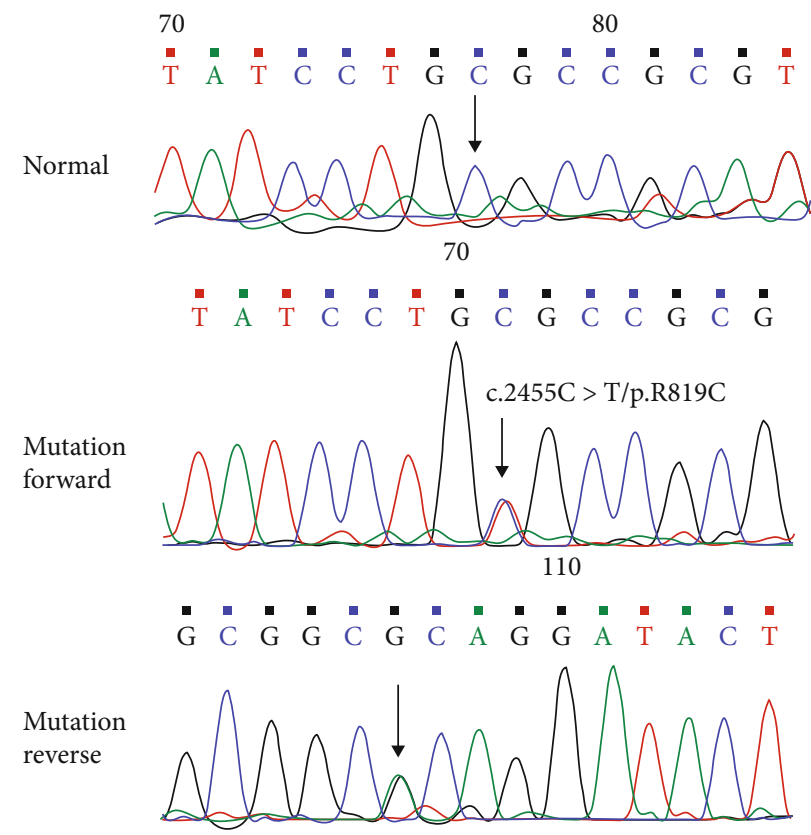

(c)

FIgure 1: Description of the family with AVB. (a) Pedigree of the family. Family members are identified by generations and numbers. Squares = males; circles $=$ females; black symbols = affected individuals; white symbols = unaffected individuals; arrow =the proband; $\mathrm{M} / \mathrm{N}=$ people carried TRPM4 mutation; $\mathrm{N} / \mathrm{N}=$ people without TRPM4 mutation. (b) The 12-lead ECGs of the proband. (c) Sanger sequencing results of the TRPM4 mutation. Sequence chromatogram indicates a C to T transition of nucleotide 2455.

TABLE 1: Demographic and clinic features in members of the family.

\begin{tabular}{lcccc}
\hline Family members & Sex & Age (year) & EGC & History \\
\hline Proband (III-1) & Female & 10 & High-grade AVB & Syncope \\
II-1 & Female & 35 & - & - \\
II-2 & Male & 40 & PR interval delayed & Syncope \\
II-3 & Female & 37 & - & - \\
I-1 & Female & $34^{*}$ & - & Sudden death \\
I-2 & Male & 66 & - & - \\
\hline
\end{tabular}

*Age of death.

G844D in TRPM4. The increased cell surface conductance may affect electrical signal transmission along the Purkinje fibers. The abnormal action potential propagation causes cardiac conduction disorder [25]. Currently, mutations in TRPM4 were identified in autosomal recessive Brugada syndrome and Progressive Symmetric Erythrokeratodermia (PSEK). As Wang et al. discussed, most of the mutations that caused PSEK were located in the S6 transmembrane segment of TRPM4. This may keep an effective channel for electrical signal transmission $[10,26]$.

\section{Conclusions}

In conclusion, we identify a novel TRPM4 mutation (c.2455C>T/p.R819C) in a two-generation family with AVB by genetic sequencing. The present study, in which a novel 
TABLE 2: Variants identified by WES in combination with cardiomyopathy-related gene filter in the family.

\begin{tabular}{|c|c|c|c|c|c|c|c|c|c|}
\hline CHR & POS & $\mathrm{RB}$ & $\mathrm{AB}$ & $\begin{array}{l}\text { Gene } \\
\text { name }\end{array}$ & AA change & MutationTaster & PolyPhen-2 & SIFT & $\begin{array}{c}\text { ACMG } \\
\text { statement }\end{array}$ \\
\hline chr1 & 100342136 & $\mathrm{G}$ & $\mathrm{A}$ & AGL & $\begin{array}{c}\text { AGL:NM_ } \\
\text { 000645:exon9:c.G1355A:p.R452Q }\end{array}$ & $\begin{array}{l}\text { Disease causing } \\
\text { (1) }\end{array}$ & $\begin{array}{c}\text { Probably } \\
\text { damaging } \\
(0.902)\end{array}$ & $\begin{array}{l}\text { Tolerated } \\
(0.065)\end{array}$ & BS4 \\
\hline chr1 & 228527780 & $\mathrm{C}$ & $\mathrm{T}$ & OBSCN & $\begin{array}{c}\text { OBSCN:NM_ } \\
\text { 001098623:exon70:c.C17393T:p.T5798M }\end{array}$ & $\begin{array}{l}\text { Polymorphism } \\
\quad(0.977)\end{array}$ & $\begin{array}{c}\text { Probably } \\
\text { damaging } \\
(0.877)\end{array}$ & $\begin{array}{l}\text { Damaging } \\
(0.024)\end{array}$ & BS4 \\
\hline chr6 & 170598799 & G & A & DLL1 & $\begin{array}{c}\text { DLL1:NM_ } \\
\text { 005618:exon2:c.C152T:p.P51L }\end{array}$ & $\begin{array}{l}\text { Polymorphism } \\
\quad(0.998)\end{array}$ & $\begin{array}{l}\text { Benign } \\
(0.037)\end{array}$ & $\begin{array}{l}\text { Tolerated } \\
(0.71)\end{array}$ & $\mathrm{BP} 4$ \\
\hline chr7 & 154379618 & $\mathrm{G}$ & $\mathrm{C}$ & DPP6 & $\begin{array}{c}\text { DPP6:NM_ } \\
\text { 001290253:exon6:c.G886C:p.V296L }\end{array}$ & $\begin{array}{l}\text { Disease causing } \\
\text { (1) }\end{array}$ & $\begin{array}{l}\text { Benign } \\
(0.033)\end{array}$ & $\begin{array}{l}\text { Damaging } \\
\quad(0)\end{array}$ & BS4 \\
\hline chr11 & 2906376 & $\mathrm{~A}$ & $\mathrm{C}$ & CDKN1C & $\begin{array}{l}\text { CDKN1C:NM_ } \\
\text { 000076:exon1:c.T344G:p.V115G }\end{array}$ & $\begin{array}{l}\text { Polymorphism } \\
\text { (1) }\end{array}$ & $\begin{array}{l}\text { Benign } \\
(0.011)\end{array}$ & $\begin{array}{l}\text { Tolerated } \\
(0.089)\end{array}$ & BP4 \\
\hline $\operatorname{chr} 12$ & 116445394 & $\mathrm{~T}$ & $\mathrm{C}$ & MED13L & $\begin{array}{c}\text { MED13L:NM_ } \\
\text { 015335:exon11:c.A2060G:p.Q687R }\end{array}$ & $\begin{array}{l}\text { Polymorphism } \\
\quad(0.902)\end{array}$ & $\begin{array}{l}\text { Benign } \\
(0.001)\end{array}$ & $\begin{array}{l}\text { Tolerated } \\
(0.859)\end{array}$ & $\mathrm{BP} 4$ \\
\hline $\operatorname{chr} 19$ & 49703979 & $\mathrm{C}$ & $\mathrm{T}$ & TRPM4 & $\begin{array}{c}\text { TRPM4:NM_ } \\
\text { 001195227:exon18:c.C2455T:p.R819C }\end{array}$ & $\begin{array}{l}\text { Disease causing } \\
\text { (1) }\end{array}$ & $\begin{array}{l}\text { Damaging } \\
\text { (1) }\end{array}$ & $\begin{array}{l}\text { Damaging } \\
\quad(0)\end{array}$ & $\begin{array}{c}\text { PM2, } \\
\text { PP1, PP3, } \\
\text { PM1 }\end{array}$ \\
\hline chr20 & 10393636 & $\mathrm{G}$ & $\mathrm{A}$ & MKKS & $\begin{array}{c}\text { MKKS:NM_ } \\
\text { 018848:exon3:c.C527T:p.A176V }\end{array}$ & $\begin{array}{l}\text { Polymorphism } \\
\text { (1) }\end{array}$ & $\begin{array}{l}\text { Benign } \\
(0.011)\end{array}$ & $\begin{array}{c}\text { Tolerated } \\
(0.256)\end{array}$ & $\mathrm{BP} 4$ \\
\hline $\operatorname{chr} 20$ & 10393860 & G & $\mathrm{T}$ & MKKS & $\begin{array}{c}\text { MKKS:NM_ } \\
\text { 018848:exon3:c.C303A:p.N101K }\end{array}$ & $\begin{array}{l}\text { Polymorphism } \\
\quad(0.965)\end{array}$ & $\begin{array}{l}\text { Benign } \\
(0.324)\end{array}$ & $\begin{array}{c}\text { Tolerated } \\
(0.216)\end{array}$ & BP4 \\
\hline chr21 & 43531589 & G & $\mathrm{C}$ & UMODL1 & $\begin{array}{l}\text { UMODL1:NM_ } \\
\text { 001199527:exon11:c.G2041C:p.D681H }\end{array}$ & $\begin{array}{l}\text { Polymorphism } \\
\text { (1) }\end{array}$ & $\begin{array}{l}\text { Benign } \\
(0.007)\end{array}$ & $\begin{array}{l}\text { Damaging } \\
(0.011)\end{array}$ & BP4 \\
\hline
\end{tabular}

$\mathrm{CHR}=$ chromosome $\mathrm{POS}=$ position $; \mathrm{RB}=$ reference sequence base $\mathrm{AB}=$ alternative base identified .

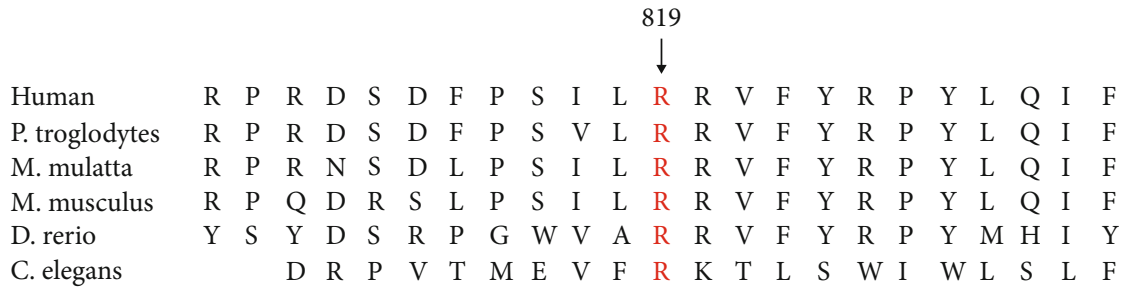

(a)

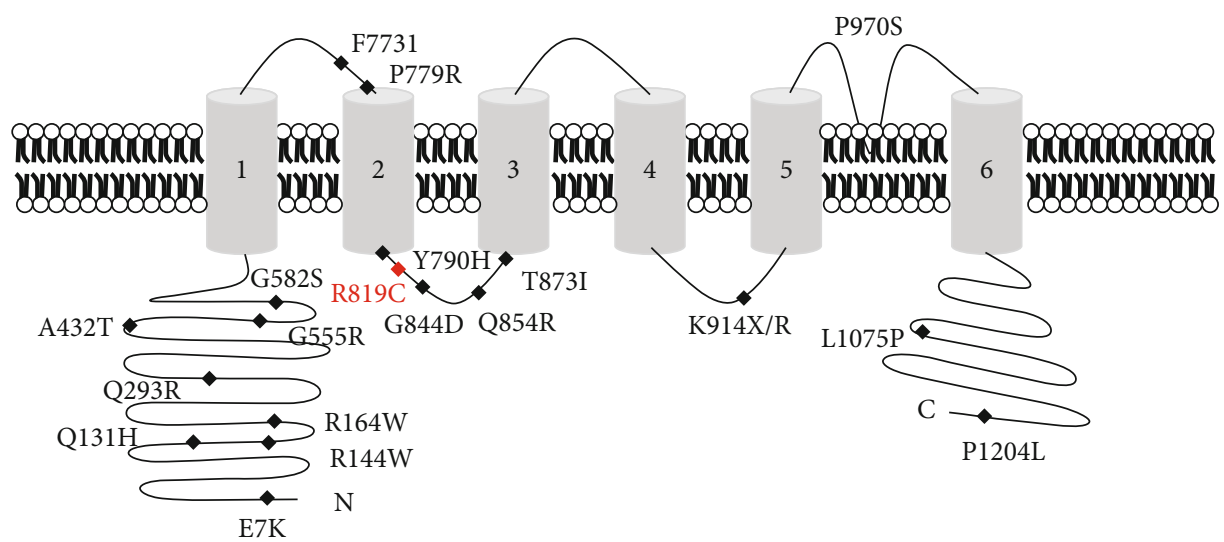

(b)

FIgURE 2: The bioinformatics analysis and summary of TRPM4 mutations. (a) Alignment of multiple TRPM4 protein sequences across species. The R819 affected amino acid locates in the highly conserved amino acid region in different mammals (from Ensembl). Red words show the R819 site. (b) Schematic diagram of TRPM4, all the domains, and location of known mutations are labeled. The novel mutation is shown in red. The mutations identified in AVB were shown in blue. 
mutation of TRPM4 was identified, not only further explain the possible cause of AVB in the family but also expand the spectrum of TRPM4 mutations and contribute to genetic diagnosis and counseling for families with AVB.

\section{Data Availability}

The data supporting the conclusions are included in the article. The datasets used and/or analyzed during the current study are available from the corresponding author upon reasonable request.

\section{Conflicts of Interest}

The authors declare that there is no conflict of interest.

\section{Authors' Contributions}

Yi Dong and Ran Du contributed equally to this work.

\section{Acknowledgments}

We thank the patients and their families for participating in this study. This work was supported by the National Science and Technology Major Project of the Ministry of Science and Technology of China (2017ZX10103005-006), the National Natural Science Foundation of China (81970403 and 82000427), the Natural Science Foundation of Hunan Province of China (2019JJ2645), and the Open Sharing Fund for the Large-Scale Instruments and Equipments of Central South University (CSUZC201940).

\section{Supplementary Materials}

Table S1: the arrhythmia-related gene list. All the genes in the list have been reported to involve in the occurrence of arrhythmia. It was used to filter the proband's candidate mutations. (Supplementary Materials)

\section{References}

[1] S. G. Priori, A. A. Wilde, M. Horie et al., "HRS/EHRA/APHRS expert consensus statement on the diagnosis and management of patients with inherited primary arrhythmia syndromes:," Heart Rhythm, vol. 10, no. 12, pp. 1932-1963, 2013.

[2] J. M. Packard, J. S. Graettinger, and A. Graybiel, "Analysis of the electrocardiograms obtained from 1000 young healthy aviators; ten year follow-up," Circulation, vol. 10, no. 3, pp. 384400, 1954.

[3] K. Ekström, J. Lehtonen, H. K. Nordenswan et al., "Sudden death in cardiac sarcoidosis: an analysis of nationwide clinical and cause-of-death registries," European Heart Journal, vol. 40, no. 37, pp. 3121-3128, 2019.

[4] X. Zhao, C. Sun, M. Cao, and H. Li, "Atrioventricular block can be used as a risk predictor of clinical atrial fibrillation," Clinical Cardiology, vol. 42, no. 4, pp. 452-458, 2019.

[5] J. S. Uhm, J. Shim, J. Wi et al., "First-degree atrioventricular block is associated with advanced atrioventricular block, atrial fibrillation and left ventricular dysfunction in patients with hypertension," Journal of Hypertension, vol. 32, no. 5, pp. 1115-1120, 2014, discussion 1120.
[6] D. F. Dickinson and O. Scott, "Ambulatory electrocardiographic monitoring in 100 healthy teenage boys," British Heart Journal, vol. 51, no. 2, pp. 179-183, 1984.

[7] H. Zhao, B. F. Cuneo, J. F. Strasburger, J. C. Huhta, N. L. Gotteiner, and R. T. Wakai, "Electrophysiological characteristics of fetal atrioventricular block," Journal of the American College of Cardiology, vol. 51, no. 1, pp. 77-84, 2008.

[8] F. B. Mollerach, M. Scolnik, L. J. Catoggio, J. Rosa, and E. R. Soriano, "Causes of fetal third-degree atrioventricular block and use of hydroxychloroquine in pregnant women with Ro/La antibodies," Clinical Rheumatology, vol. 38, no. 8, pp. 2211-2217, 2019.

[9] E. L. Kiehl, T. Makki, R. M. Matar et al., "Incidence and predictors of late atrioventricular conduction recovery among patients requiring permanent pacemaker for complete heart block after cardiac surgery," Heart Rhythm, vol. 14, no. 12, pp. 1786-1792, 2017.

[10] H. Wang, Z. Xu, B. H. Lee et al., "Gain-of-function mutations in TRPM4 activation gate cause progressive symmetric erythrokeratodermia," The Journal of Investigative Dermatology, vol. 139, no. 5, pp. 1089-1097, 2019.

[11] R. Burt, B. M. Graves, M. Gao et al., "9-Phenanthrol and flufenamic acid inhibit calcium oscillations in HL-1 mouse cardiomyocytes," Cell Calcium, vol. 54, no. 3, pp. 193-201, 2013.

[12] M. Kruse and O. Pongs, "TRPM4 channels in the cardiovascular system," Current Opinion in Pharmacology, vol. 15, pp. 6873, 2014.

[13] N. Syam, S. Chatel, L. C. Ozhathil et al., "Variants of transient receptor potential melastatin member 4 in childhood atrioventricular block," Journal of the American Heart Association, vol. 5, no. 5, 2016 .

[14] X. Daumy, M. Y. Amarouch, P. Lindenbaum et al., "Targeted resequencing identifies TRPM4 as a major gene predisposing to progressive familial heart block type I," International Journal of Cardiology, vol. 207, pp. 349-358, 2016.

[15] A. E. Baruteau, V. Probst, and H. Abriel, "Inherited progressive cardiac conduction disorders," Current Opinion in Cardiology, vol. 30, no. 1, pp. 33-39, 2015.

[16] R. Xiang, L. L. Fan, H. Huang, S. P. Zhao, and Y. Q. Chen, "Whole-exome sequencing identifies a novel mutation of DSG2 (Y198C) in a Chinese arrhythmogenic right ventricular cardiomyopathy patient," International Journal of Cardiology, vol. 214, pp. 1-3, 2016.

[17] Z. P. Tan, L. Xie, Y. Deng et al., "Whole-exome sequencing identifies Y1495X of _SCN5A_to be associated with familial conduction disease and sudden death," Scientific Reports, vol. 4, no. 1, p. 5616, 2015.

[18] R. Guinamard, P. Bouvagnet, T. Hof, H. Liu, C. Simard, and L. Sallé, "TRPM4 in cardiac electrical activity," Cardiovascular Research, vol. 108, no. 1, pp. 21-30, 2015.

[19] I. Mathar, M. Kecskes, G. van der Mieren et al., "Increased $\beta$ adrenergic inotropy in ventricular myocardium from Trpm4-/mice," Circulation Research, vol. 114, no. 2, pp. 283-294, 2014.

[20] G. Jacobs, W. Oosterlinck, T. Dresselaers et al., "Enhanced $\beta$ adrenergic cardiac reserve in Trpm $4^{-}$mice with ischaemic heart failure," Cardiovascular Research, vol. 105, no. 3, pp. 330-339, 2015.

[21] A. Pironet, N. Syam, F. Vandewiele et al., "AAV9-mediated overexpression of TRPM4 increases the incidence of stressinduced ventricular arrhythmias in mice," Frontiers in Physiology, vol. 10, p. 802, 2019. 
[22] M. Kruse, E. Schulze-Bahr, V. Corfield et al., "Impaired endocytosis of the ion channel TRPM4 is associated with human progressive familial heart block type I," The Journal of Clinical Investigation, vol. 119, no. 9, pp. 2737-2744, 2009.

[23] H. Liu, L. el Zein, M. Kruse et al., "Gain-of-function mutations in TRPM4 cause autosomal dominant isolated cardiac conduction disease," Circulation. Cardiovascular Genetics, vol. 3, no. 4, pp. 374-385, 2010.

[24] B. Stallmeyer, S. Zumhagen, I. Denjoy et al., "Mutational spectrum in the $\mathrm{Ca}(2+)$-activated cation channel gene TRPM4 in patients with cardiac conductance disturbances," Human Mutation, vol. 33, no. 1, pp. 109-117, 2012.

[25] I. Mathar, G. Jacobs, M. Kecskes, A. Menigoz, K. Philippaert, and R. Vennekens, "Trpm4," Handbook of Experimental Pharmacology, vol. 222, pp. 461-487, 2014.

[26] A. Janin, F. Bessière, T. Georgescu, V. Chanavat, P. Chevalier, and G. Millat, "TRPM4 mutations to cause autosomal recessive and not autosomal dominant Brugada type 1 syndrome," European Journal of Medical Genetics, vol. 62, no. 6, article 103527, 2019. 